OPEN ACCESS

Edited by:

Bunsho Ohtani,

Hokkaido University, Japan

Reviewed by:

Dirk Tischler,

Ruhr University Bochum, Germany

Yasushi Imada,

Tokushima University, Japan

${ }^{*}$ Correspondence:

Ljiljana Fruk

If389@cam.ac.uk

Specialty section:

This article was submitted to Catalysis and Photocatalysis,

a section of the journal

Frontiers in Chemistry

Received: 30 January 2019 Accepted: 04 April 2019

Published: 26 April 2019

Citation:

Crocker L and Fruk L (2019) Flavin

Conjugated Polydopamine

Nanoparticles Displaying Light-Driven

Monooxygenase Activity.

Front. Chem. 7:278

doi: 10.3389/fchem.2019.00278

\section{Flavin Conjugated Polydopamine Nanoparticles Displaying Light-Driven Monooxygenase Activity}

\author{
Leander Crocker and Ljiljana Fruk* \\ Department of Chemical Engineering and Biotechnology, University of Cambridge, Cambridge, United Kingdom
}

A hybrid of flavin and polydopamine (PDA) has been explored as a photocatalyst, drawing inspiration from natural flavoenzymes. Light-driven monoxygenase activity has been demonstrated through the oxidation of indole under blue light irradiation in ambient conditions, to afford indigo and indirubin dyes. Compared to riboflavin, a flavin-polydopamine hybrid is shown to be more resistant to photobleaching and more selective toward dye production. In addition, it has been demonstrated that it can be recycled from the solution and used for up to four cycles without a marked loss of activity, which is a significant improvement compared to other heterogenous flavin catalysts. The mechanism of action has been explored, indicating that the PDA shell plays an important role in the stabilization of the intermediate flavin-peroxy species, an active component of the catalytic system rather than acting only as a passive nanocarrier of active centers.

Keywords: flavin, polydopamine, light-driven reaction, monooxygenase, indole

\section{INTRODUCTION}

Flavin-containing monooxygenases (FMOs) are an important class of xenobiotic-degrading enzymes present in both eukaryotic and prokaryotic organisms. For example, they are able to add molecular oxygen to the lipophilic xenobiotic compounds, thereby increasing their solubility enough to allow excretion. As a result, organisms are protected from potentially toxic exogenous compounds derived from natural sources and, particularly important for humans, the metabolism of drugs and pollutants (Krueger and Williams, 2005; Zhou and Shephard, 2006; Hodgson, 2010). One of the substrates for FMOs, which is also widespread in nature is the $\mathrm{N}$-heterocycle indole. It is considered to be an aromatic pollutant due to its toxicity and potential mutagenicity (Sullivan and Gad, 2014), but it is also a versatile intermediate species and signaling molecule across families of organisms (Lee and Lee, 2010; Erb et al., 2015; Lee et al., 2015a,b). Indigo dyes are currently commercially produced by chemical synthesis using aniline, formaldehyde, and hydrogen cyanide to form phenylglycinonitrile, subsequently hydrolyzed to yield phenylglycine, which is finally converted to indigotin. This process involves use of toxic chemicals and extensive purification steps, limiting the environmental viability and prompting the design of more green-chemistry oriented strategies (Blackburn et al., 2009).

FMOs, as well as the other xenobiotic-degrading enzymes such as cytochrome P450s, have been shown to convert indole to the blue indigo dye through initial oxidation to indoxyl and subsequent dimerization to form the dye as shown in Scheme 1. This transformation has been utilized as an enzymatic assay to screen for oxygenases (O'Connor et al., 1997; Singh et al., 2010; Lin et al., 2012; Nagayama et al., 2015), but also as a greener alternative to the industrial manufacturing of indigo and related indigoid dyes. To achieve that, a whole cell biocatalysis relying on the cellular FMO's 

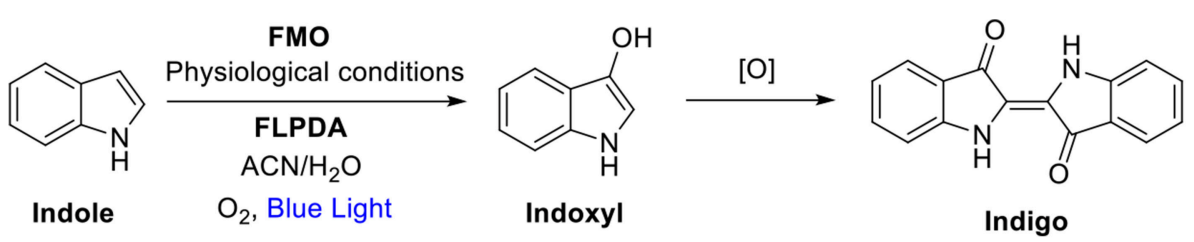

SCHEME 1 | Indole oxidation to indoxyl and further oxidation and dimerization to indigo where FMO, Flavin-containing monooxygenases; FLPDA, flavin-polydopamine; CAN, acetonitrile; [O], further oxidation processes by $\mathrm{O}_{2}$ (Mermod et al., 1986; Meyer et al., 2002).

is utilized to achieve that since the current industrial manufacturing of these dyes is highly energy demanding, results in large amounts of toxic waste products, and requires number of purification steps (Han et al., 2012; Hsu et al., 2018; Ma et al., 2018). However, a whole-cell biocatalysis is also faced with complex product separation and catalyst inhibition, which incurs large costs and reactor downtime periods (Lin and Tao, 2017). Alternatives such as the use of the isolated enzymes suffer from limited enzyme quantities, low stability under non-physiological conditions, sensitivity to organic solvents, as well as challenging post-reaction isolation, hence limiting large scale industrial applications (Reetz, 2002; Li et al., 2012).

Taken out of a protein environment, flavin analogs derived from cofactors flavin mononucleotide (FMN), flavin adenine dinucleotide (FAD) and riboflavin have shown huge potential for catalytic applications, especially in photocatalytic processes (de Gonzalo and Fraaije, 2013; König et al., 2013; Cibulka, 2015). Despite the relative ease of visible-light driven flavin photocatalysis, high yielding reactions, and low toxicity, there are still challenges related to their long-term stability and photobleaching, as well as the separation of the catalyst from the products and subsequent catalyst reuse. To address these issues, attempts have been made to immobilize flavins onto various solid carriers such as silica beads or resins to achieve a heterogeneous catalytic systems, although limited success has been reported in relation to recyclability and activity (Schmaderer et al., 2009; Špačková et al., 2017; Arakawa et al., 2018). Taking this into account, we have rationalized that the use of solid, polymeric carrier, which not only permits immobilization of flavin but also displays some intrinsic properties similar to protein shells such as H-bonding and electron transfer, could significantly improve both the activity and post-reaction recovery of the hybrid catalytic system.

Herein, we present a new strategy to design a versatile enzymeinspired photocatalytic system by embedding flavin within an active polymer matrix. We have chosen polydopamine (PDA) as the carrier polymer due to its reported biocompatibility (Hong et al., 2011; D'Ischia et al., 2014) and structural and electronic properties (Liu et al., 2014). Composed of a sequence of extended $\pi$-systems, PDA is considered to be an amorphous organic semiconductor, and has been used to improve various nanoparticle catalysts (Ma et al., 2015; Kunfi et al., 2017; Zhou et al., 2017), enhance the efficiency and stability of whole cell biocatalytic systems (Wang et al., 2017), and act as an electron gate for artificial photosynthesis due to its excellent electron accepting ability (Kim et al., 2014). Although PDA's main application has been to act as a molecular adhesive, due to its capability to form coatings on virtually any surface (Lee et al., 2007), an ability equally as interesting is its intrinsic catalytic activity (Mrõwczynski et al., 2014; Yang et al., 2014; Du et al., 2015), which has not yet been explored to afford hybrid organic systems with photocatalytic activity.

We hypothesized that monoxygenase activity of the flavinpolydopamine (FLPDA) system could be initiated through blue light irradiation to excite the flavin moieties, bypassing the use of external reducing agents or cofactors such as NADH. At the same time, PDA can be utilized as an active solid support enabling both the electron transfer and the stabilization of reactive intermediates. The latter was inspired by BLUF (blue light sensors using FAD) photoreceptors, in which an electron transfer between flavin cofactor and tyrosine in the protein shell is the key process enabling the stabilization of intermediates and switching from dark-adapted to light-adapted state, which guides biological signaling pathways (Mathes et al., 2012). In addition, the photoinduced electron transfer from tryptophan to flavin has been shown to be a crucial step in the control of CRY protein's activity, which is responsible for control of the light dependent circadian clocks in plants and animals (Lin et al., 2018). As shown in Scheme 2, the structure of PDA mimics both the tyrosine and tryptophan residues, indicating that the polymer could actively engage in electron transfer processes and impact the catalytic activity of embedded flavin. With this in mind, we focused our efforts to synthesize FLPDA nanoparticles through the co-polymerization of a flavin-dopamine monomer, FLDA, and dopamine. We then investigated the light-driven monooxygenase activity of the particles through blue light irradiation in the presence of indole under ambient conditions.

\section{EXPERIMENTAL}

\section{General}

All materials were purchased from either Acros Organics, Alfa Aeser, Sigma-Aldrich, or TCI Chemicals in the highest purity available and used without further purification. ${ }^{1} \mathrm{H}$ and ${ }^{13} \mathrm{C}$ NMR measurements were carried out using a 500 $\mathrm{MHz}$ DCH Cryoprobe Spectrometer. HRMS was recorded on a ThermoFinnigan Orbitrap Classic (Fisher Scientific). UV-Vis absorption spectra were obtained with an Agilent Cary 300 Spectrophotometer. Fluorescence emission spectra were obtained using a Varian Cary Eclipse Fluorescence 

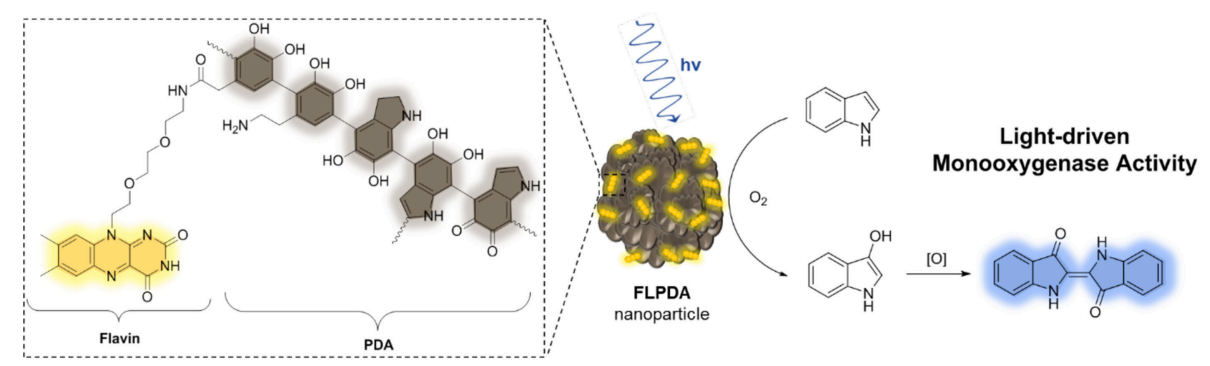

SCHEME 2 | Structure of flavin-polydopamine (FLPDA) units (left) and the reaction scheme illustrating explored light-driven oxidation of indole to indigo in presence of FLPDA nanoparticles (right).

Spectrophotometer using excitation and emission slits of $10 \mathrm{~nm}$. DLS and Zeta Potential measurements were recorded using a Zetasizer Nano Range instrument (Malvern Panalytical). FTIR spectroscopy was carried out using a Bruker Tensor 27 spectrometer with samples pressed into $\mathrm{KBr}$ pellets. STEM images were obtained using a Hitachi S-5500 In-Lens FE STEM (2009) at an acceleration voltage of $1.0 \mathrm{kV}$. Samples were suspended in water and drop cast on lacey carbon copper grids (Agar Scientific). HPLC was carried out on an Agilent 1260 Infinity Quaternary LC equipped with a Zorbax Eclipse Plus C18 column $(5 \mu \mathrm{m}, 4.6 \times 1.5 \mathrm{~mm}$, Agilent $)$ and diode array detector (monitoring at $270 \mathrm{~nm}$ ). The mobile phase consisted of Solvent $\mathrm{A}$ (water $+0.1 \%$ formic acid) and solvent B ( $\mathrm{ACN} / \mathrm{MeOH}$, 50:50, v/v) running along the following gradient: $0-8 \mathrm{~min} 85 \%$ $\mathrm{A}$ and $15 \% \mathrm{~B}$ at a flow rate of $1 \mathrm{~mL} / \mathrm{min}, 8-15 \mathrm{~min} 65 \% \mathrm{~A}$ and $35 \% \mathrm{~B}$ at a flow rate of $2 \mathrm{~mL} / \mathrm{min}$. Indole (99\%), isatin (97\%), and oxindole (98\%) were purchased from Sigma-Aldrich and calibration curves were obtained from 0 to $1.0 \mathrm{mM}$ stock solutions in order to estimate product concentrations and \% conversions. LC-MS was performed on an Agilent G6550 QTof mass spectrometer coupled to an Agilent 1200 Series Infinity LC system using a Zorbax Eclipse Plus C18 column $(5 \mu \mathrm{m}, 4.6 \times$ $1.5 \mathrm{~mm}$, Agilent). The mobile phase consisted of Solvent A (water $+0.1 \%$ formic acid) and solvent $\mathrm{B}(\mathrm{ACN}+0.1 \%$ formic acid $)$ running along the following gradient: $0-14 \mathrm{~min} 85 \% \mathrm{~A}$ and $15 \% \mathrm{~B}$ to $5 \% \mathrm{~A}$ and $95 \% \mathrm{~B}$ at a flow rate of $0.8 \mathrm{~mL} / \mathrm{min}$. The electrospray source was operated with a capillary voltage of $3.0 \mathrm{kV}$ and a nozzle voltage of $1.0 \mathrm{kV}$. Nitrogen was used as the desolvation gas at a total flow of $14 \mathrm{~L} / \mathrm{min}$. All $\mathrm{m} / z$ values stated are that of the $[\mathrm{M}+\mathrm{H}]^{+}$molecular ion.

\section{Synthesis of FLDA Monomer}

See section Synthesis of Flavin-Dopamine Monomer in Supplementary Information for full synthetic details.

\section{Synthesis of FLPDA}

A mixture of ammonia solution $(0.1 \mathrm{~mL}, 28 \%)$, ethanol $(1.5 \mathrm{~mL})$, and Milli Q water $(4.5 \mathrm{~mL})$ was stirred at room temperature for $30 \mathrm{~min}$ in reaction vessels protected from direct sunlight. Dopamine hydrochloride $(15.80 \mathrm{mg}, 0.083 \mathrm{mmol})$ dissolved in Milli-Q water $(0.5 \mathrm{~mL})$ and FLDA $(8.73 \mathrm{mg}, 0.017 \mathrm{mmol})$ dissolved in ethanol $(0.5 \mathrm{~mL})$ were mixed before being added dropwise to the reaction mixture. The resulting dark brown/black mixture was left to stir in the presence of air for $24 \mathrm{~h}$. The mixture was then centrifuged at $25,000 \times \mathrm{g}$ for $30 \mathrm{~min}$ and the supernatant was removed. The precipitate was washed with Milli-Q water $(3 \times 40 \mathrm{~mL})$ and then suspended in Milli-Q water $(20 \mathrm{~mL})$, frozen in liquid $\mathrm{N}_{2}$ and lyophilized to yield a dark brown/black powder $(5.5 \mathrm{mg}, \rho=22 \%$ where $\rho$ is the percent weight conversion of monomers) (Jiang et al., 2014).

\section{Photooxidation of Indole}

FLPDA (0.01-0.1 mg/mL) and indole (0.2 $\mu \mathrm{mol}-0.05 \mathrm{mmol})$ were added to a 50:50 acetonitrile/water $(2 \mathrm{~mL})$ solvent system and the mixture was saturated with $\mathrm{O}_{2}$ gas for $10 \mathrm{~min}$ before irradiating with a custom-made blue LED strips setup $(12 \mathrm{~V})$ with a cooling fan to maintain a temperature of $\sim 25^{\circ} \mathrm{C}$ (see Figure S1 for setup). For small scale reactions, $100 \mu \mathrm{L}$ aliquots were taken from the reaction mixture and diluted to $1 \mathrm{~mL}$ (50:50 acetonitrile/water) for analysis by UV-Vis absorption spectroscopy. Post-irradiation (2-6h), the reaction mixture was either diluted in 50:50 acetonitrile/water $(10 \mathrm{~mL})$ and the catalyst removed by centrifugation and washed with water $(3 \times 12 \mathrm{~mL})$ for further use, or the catalyst was removed by centrifugation and the supernatant analyzed by HPLC-UV and LC-MS. For larger scale reactions the resulting supernatant was concentrated under reduced pressure and residue analyzed by ESI-MS and UV-Vis absorption spectroscopy.

\section{RESULTS AND DISCUSSION}

\section{Synthesis of Flavin-Polydopamine}

FLPDA nanoparticles were formed by the copolymerization of dopamine (DA) with the flavin derivative, FLDA that was synthesized according to the route shown in Scheme 3. First, the functionalized triethylene glycol species, 1 (Deng et al., 2011) was used in a mono-substitution reaction with 4,5-dimethylbenzene1,2-diamine to form $N^{1}$-(2-(2-(2-azidoethoxy)ethoxy)ethyl)-4,5dimethylbenzene-1,2-diamine, 2 .

Isoalloxazine formation was achieved through the double condensation reaction with alloxan monohydrate to obtain flavin derivative 3 . The azide functionality was then reduced via catalytic hydrogenation to yield the amine-bearing flavin derivative 4. Conjugation of this compound to the activated 


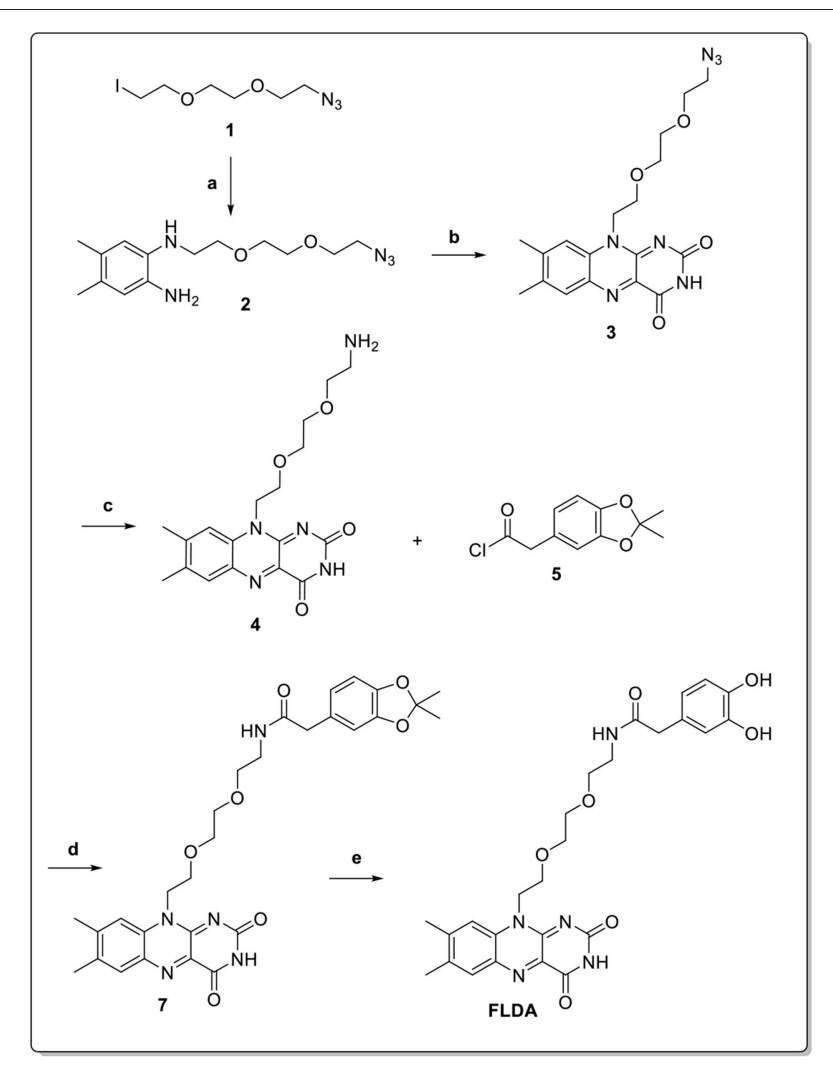

SCHEME 3 | Reaction conditions: (a) 4,5-dimethylbenzene-1,2-diamine, $\mathrm{K}_{2} \mathrm{CO}_{3}, \mathrm{DMF}, 50{ }^{\circ} \mathrm{C}, 12 \mathrm{~h}(70 \%)$; (b) alloxan monohydrate, $\mathrm{B}_{2} \mathrm{O}_{3}, \mathrm{AcOH}, \mathrm{RT}$, dark, $48 \mathrm{~h}$ (69\%); (c) Pd/C, $\mathrm{H}_{2}$, AcOH, RT, dark, $18 \mathrm{~h}$ (84\%); (d) TEA, DMF, RT, dark, $18 \mathrm{~h}$ (62\%); (e) TFA/DCM, RT, dark, 2 h (99\%).

catechol-protected dopamine analog 6 resulted in protected FLDA derivative 7, which was subsequently deprotected to afford the target FLDA monomer. Co-polymerization of dopamine and FLDA was carried out following a room temperature procedure adapted from Ai et al. (2013), and using ammonia addition to a water/ethanol solvent system in the presence of air. It should be noted that the reaction vessels were protected from direct light exposure to avoid any possible side reactions through the excitation of flavin moieties.

To validate the presence of flavin moieties, FLPDA was first analyzed by UV-Vis absorption and fluorescence spectroscopy. UV-Vis spectra of FLDA monomer shows absorption bands at $\lambda_{\max }=445 \mathrm{~nm}$ and $373 \mathrm{~nm}$ (Figure 1A) corresponding to the transitions from the ground state $\left(S_{0}\right)$ to the $S_{1}\left(\lambda_{\max } \sim 442-\right.$ $450 \mathrm{~nm})$ and $S_{2}\left(\lambda_{\max } \sim 360-375 \mathrm{~nm}\right)$ excited states (Heelis, 1982). These bands are red-shifted to $\sim 456 \mathrm{~nm}$ for the $S_{0} \rightarrow$ $S_{1}$ transition and $\sim 376 \mathrm{~nm}$ for the $S_{0} \rightarrow S_{2}$ transition in FLPDA (Figure 1B), which can be explained by an increase in proton donation from PDA (Kotaki et al., 1970) and by electron-withdrawing inductive effects on the flavin moieties due to incorporation into the highly conjugated PDA system (Mataranga-Popa et al., 2015). The fluorescence emission spectra of FLDA and FLPDA are characterized by emission maxima at $527 \mathrm{~nm}\left(\lambda_{\text {ex }}=450 \mathrm{~nm}\right)$, which correlates well to other known flavin compounds (Kotaki and Yagi, 1970), and confirms the presence of flavin moieties in FLPDA NPs (see Figures 1C,D). An earlier study in which flavin compounds were complexed with eumelanin showed that the fluorescent properties of flavins did not change upon binding and there is no significant fluorescence quenching by the polymer (Kozik et al., 1990). We have used this fact to approximate flavin concentration within FLPDA by means of a calibration curve comparison (see Figure S2 and Table S2). This gave an approximate concentration of flavin within FLPDA at $279.7 \mathrm{nmol} / \mathrm{mg}$. It is worth noting that the amounts of flavin do not exactly match the monomer ratio used to synthesize the particles. The reason for this could be either the engulfing of the flavin moieties within particles or the base catalyzed cleavage/hydrolysis of flavin moieties during the polymerization, which results in the loss of characteristic flavin fluorescence (Smith and Bruice, 1975; Harayama et al., 1984).

FTIR spectroscopy was additionally employed to confirm FLPDA composition. The spectrum of PDA (Figure 2A) shows characteristic bands at $3,356 \mathrm{~cm}^{-1}$ relating to $\mathrm{O}-\mathrm{H}$ and $\mathrm{N}-\mathrm{H}$ stretching vibrations. In FLDA spectrum the bands corresponding to these vibrations broadens into one band at $3,414 \mathrm{~cm}^{-1}$, which is also the case for FLPDA. Unlike for PDA, in the spectra of FLPDA bands at 2,924 and 2,855 $\mathrm{cm}^{-1}$ corresponding to $\mathrm{C}-\mathrm{H}$ stretching vibration can be clearly identified and correlated well to the spectrum of FLDA. As seen in the zoomed spectra in Figure $\mathbf{2 B}$, bonds characteristic for flavins such as the sharp bands at $1,545 \mathrm{~cm}^{-1}$ and $1,580 \mathrm{~cm}^{-1}$ relating to $\nu(C=N)$ modes in the isoalloxazine ring (Rieff et al., 2011) can clearly be observed in FLPDA, This is also true for the contributions from flavin carbonyl $v(C=O)(1,711$ and $\left.1,680 \mathrm{~cm}^{-1}\right)$ and $\nu(C=C)$. In addition, there are $\mathrm{C}=\mathrm{O}$ and C-O vibrational modes of PDA, seen at 1,610 and $1,512 \mathrm{~cm}^{-1}$, respectively, which are not observed in FLDA. Further $\mathrm{C}=\mathrm{N}$ and $\mathrm{C}=\mathrm{C}$ combined contributions can also be seen at shifted wavenumbers in the spectrum of FLPDA $\left(1,292 \mathrm{~cm}^{-1}\right)$.

Finally, the size and morphology of FLPDA were investigated using STEM. As shown in Figure 3 FLPDA solution is made up of spherical particles of similar size $(\sim 200 \mathrm{~nm})$ with relatively large size distribution $( \pm \sim 50 \mathrm{~nm}$ ) (see Table S1). In contrast, PDA synthesized under the same conditions displays a narrower size distribution with an average size of $110 \pm 18 \mathrm{~nm}$ (see Table S1), clearly indicating that the presence of flavin moieties affects the polymerization mechanism and oligomer aggregation to form particles with less defined shape and size. This is most likely due to H-bonding and electrostatic interactions between the flavin group and oligomeric units, and our ongoing work is focused on optimizing the polymerization procedure.

\section{Indole Photooxidation}

Having successfully prepared and characterized the FLPDA nanoparticles, we set out to investigate their catalytic activity in the presence of indole under blue light irradiation and explored their resemblance to the FMO enzyme activity. At first, small scale reactions were carried out using $1.0 \mathrm{mM}$ indole with $50 \mu \mathrm{g} / \mathrm{mL}$ FLPDA and monitored by UV-Vis absorption spectroscopy. As shown in Figure 4A the absorption spectrum of indole $(0 \mathrm{~h})$ has a characteristic absorbance band at $\lambda_{\max }=$ $287 \mathrm{~nm}$. After $0.5 \mathrm{~h}$ irradiation, this peak decreases in intensity and a new band appears at $\lambda_{\max } \sim 380 \mathrm{~nm}$ which is consistent 

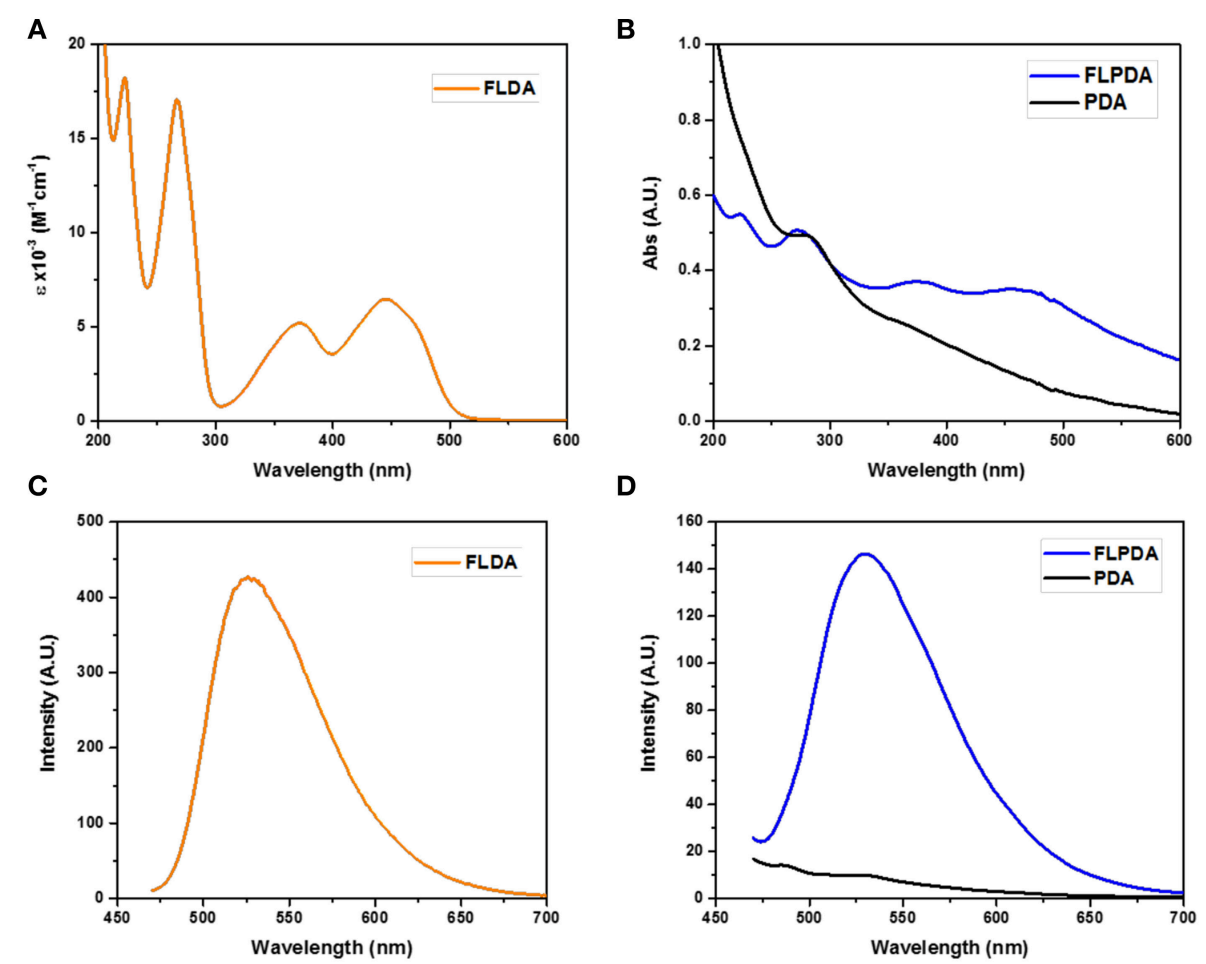

FIGURE 1 | UV-Vis spectra of FLDA (80 $\mu \mathrm{M}, 0.04 \mathrm{mg} / \mathrm{mL}$ in water (A), and FLPDA and PDA (0.1 mg/mL in water (B), and corresponding fluorescence spectra (C,D).
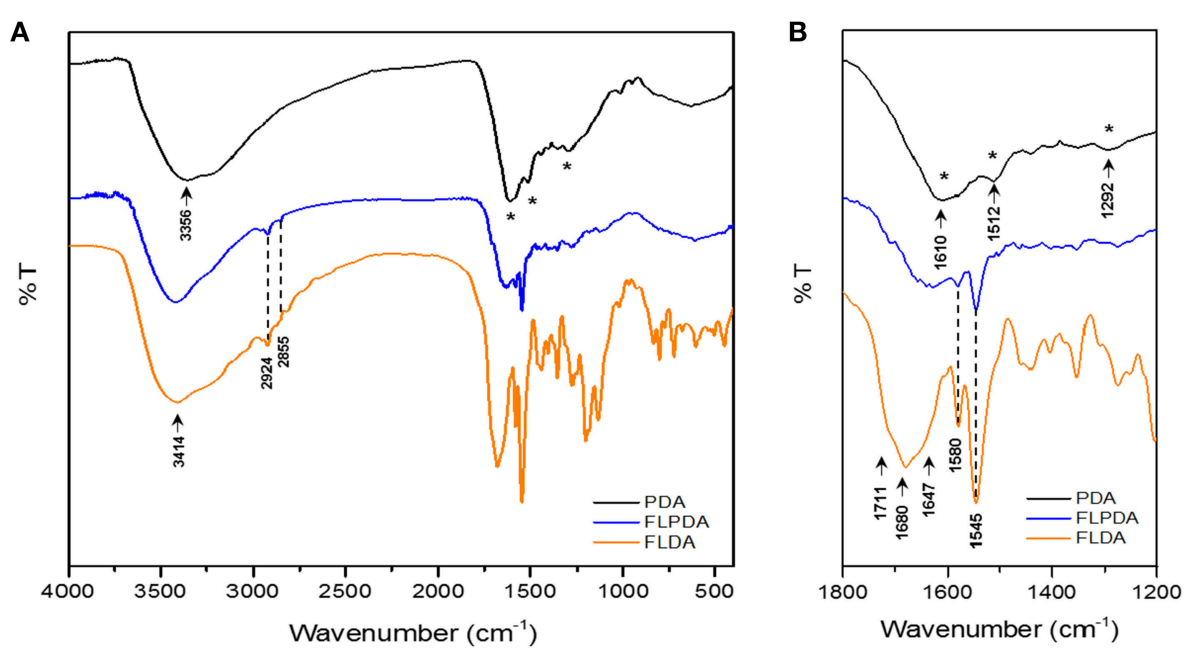

FIGURE 2 | Full-scale FTIR (A) and zoomed (B) spectra of PDA, FLPDA, and FLDA.

with the consumption of indole and the production of 2 and 3position hydroxylated indole species (Kumar and Kumar, 1998; Kuo and Mauk, 2012; Linhares et al., 2014). These bands increase in intensity with time and a shoulder replacing the characteristic band belonging to indole at $2 \mathrm{~h}$ indicates its consumption (KuO and Mauk, 2012). We also monitored the fluorescence emission $\left(\lambda_{\mathrm{ex}}=365 \mathrm{~nm}\right)$ of the reaction as shown in Figure $4 \mathrm{~B}$ and observed the formation of fluorescent indoxyl species $\left(\lambda_{\mathrm{em}}=\right.$
$465 \mathrm{~nm}$ ) at $0.5 \mathrm{~h}$ and $1 \mathrm{~h}$ (Gehauf and Goldenson, 1957; Woo et al., 2000). After $1 \mathrm{~h}$ the signal disappears most likely due to indoxyl dimerization into the fluorescent, water-soluble leucoindigo ( $\lambda_{\mathrm{em}}=523 \mathrm{~nm}$ ) (Gehauf and Goldenson, 1957; Seixas De Melo et al., 2004). Control experiments were carried out in the dark showing no reaction after $18 \mathrm{~h}$, and by irradiating indole alone, indole in the presence of pure PDA particles, and indole in the presence of FLPDA under inert Ar atmosphere; all of which 

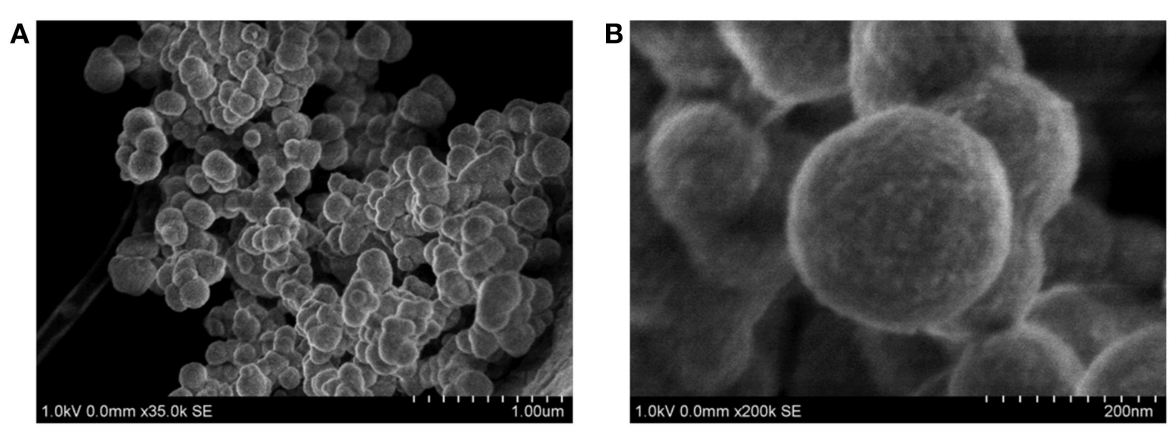

FIGURE 3 | STEM images of FLPDA at different scales (A) scale bar $=1.00 \mu \mathrm{m}$ and $\mathbf{( B )}$ scale bar $=200 \mathrm{~nm}$.
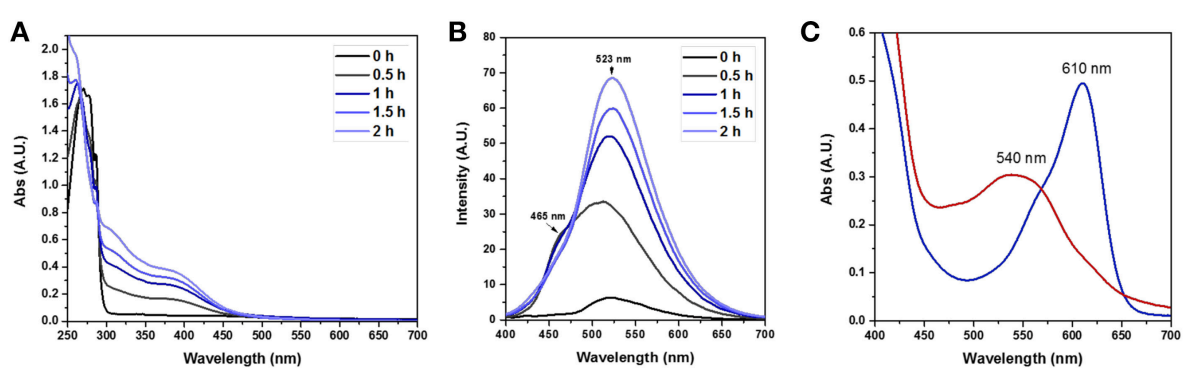

FIGURE 4 | (A) UV-Vis absorption spectra of the photooxidation of indole (1.0 mM) in the presence of FLPDA $(50 \mu \mathrm{g} / \mathrm{mL})$ in $\mathrm{O}_{2}$ saturated $\mathrm{ACN} / \mathrm{H}_{2} \mathrm{O}(1: 1, \mathrm{v} / \mathrm{v})$. (B) Fluorescence emission spectra $\left(\lambda_{e x}=380 \mathrm{~nm}\right)$ of indole $(1.0 \mathrm{mM})$ photooxidation in the presence of FLPDA $(50 \mu \mathrm{g} / \mathrm{mL})$ in $\mathrm{O}_{2}$ saturated $\mathrm{ACN} / \mathrm{H}_{2} \mathrm{O}(1: 1, \mathrm{v} / \mathrm{v})$. All spectra are $10 \times$ dilutions of reaction mixture. (C) UV-Vis absorption spectra of produced indirubin $(\lambda \max =540 \mathrm{~nm})$ and indigo $(\lambda$ max $=610 \mathrm{~nm})$ in DMF.

showed negligible changes in indole's characteristic absorption band (see Figure S3).

Several oxidation products were obtained from the FLPDA catalyzed photooxidation of indole and three major products were identified by LC-MS (Figure 5) and compared to the commercial reagents. These were isatin 11 (7.07 $\mathrm{min}, \mathrm{m} / z$ : 148), 2-oxindole 9 ( $7.69 \mathrm{~min}, \mathrm{~m} / \mathrm{z}$ : 134), and indoxyl 10 observed as its more stable keto-form 10a (4.23 $\mathrm{min}, m / z: 132)$. Other products with higher $m / z$ values were also identified via LC-MS of the reaction mixture, including indigo/indirubin (two signals with $\mathrm{m} / \mathrm{z}: 263$ ) and two others with $\mathrm{m} / \mathrm{z}$ values of 249 and 281 . Their structures are proposed in Scheme 4 and Figure S5 as products 12 and 13, and their production is particularly interesting as they were observed in reactions catalyzed by enzymes such as laccases and P450s that contain inorganic cofactors (Gillam et al., 2000; Ganachaud et al., 2008; Linhares et al., 2014).

The formation of indigo and indirubin were initially observed by TLC analysis of the reaction mixture and were then isolated after reaction workup and characterized by UV-Vis (indirubin $\lambda_{\max }=540 \mathrm{~nm}$ and indigo $\lambda_{\max }=610 \mathrm{~nm}$ as seen in Figure 4C). It should be noted that theses dyes were not observed to form during the reaction itself, but only upon removal of the solvent to initiate precipitation or with the addition of weak acid to the reaction mixture or supernatant which catalyzed their formation (Zelentskii et al., 1970). Yields of the dyes were measured by UVVis spectroscopy using published extinction coefficients (Seixas De Melo et al., 2004) and were generally low (<4\%) when precipitated out of solution after solvent removal however this is comparable to other biomimetic systems using $\mathrm{Fe}(\mathrm{II})$ and $\mathrm{Mn}$ (III) porphyrin complexes in the presence of $\mathrm{H}_{2} \mathrm{O}_{2}$ (Linhares et al., 2014; Rebelo et al., 2014) indicating that low yields are the consequence of the non-specific binding sites, as the active site of FMO alters the product selectivity (Han et al., 2012). We noticed that adding weak acid to the reaction mixture after irradiation provided better yields of dye, however, primarily favored the formation of indirubin (see Table 1).The light-driven oxidation of indole by FLPDA is clearly non-specific due to the range of identified oxidation products, however, these main products resemble those formed by FMOs and other xenobiotic degrading enzymes. To our knowledge, this is the only reported example of an organic nanoparticle-based photocatalyst that shows this activity. In addition, the only other example of photocatalytic oxidation of indole to form indigo and related compounds are CdS quantum dots, the use of which has serious implications in terms of toxicity (Tsoi et al., 2013; Yong et al., 2013).

We also compared the activity of our hybrid catalyst to homogenous flavin, riboflavin (RF), under the same reaction conditions. To make an experimentally valid comparison, we used the same effective flavin concentration for both FLPDA and RF based on the fluorescence calibration curve utilized to characterize FLPDA, namely $20 \mu \mathrm{M}$ for RF ( $2 \mathrm{~mol} \%$ ) and $36 \mu \mathrm{g} / \mathrm{mL}$ FLPDA. UV-Vis analysis of the reaction mixture containing RF showed an increased rate of indole consumption (shoulder formation at $\sim 280 \mathrm{~nm}$ as shown in Figure 7A) after 

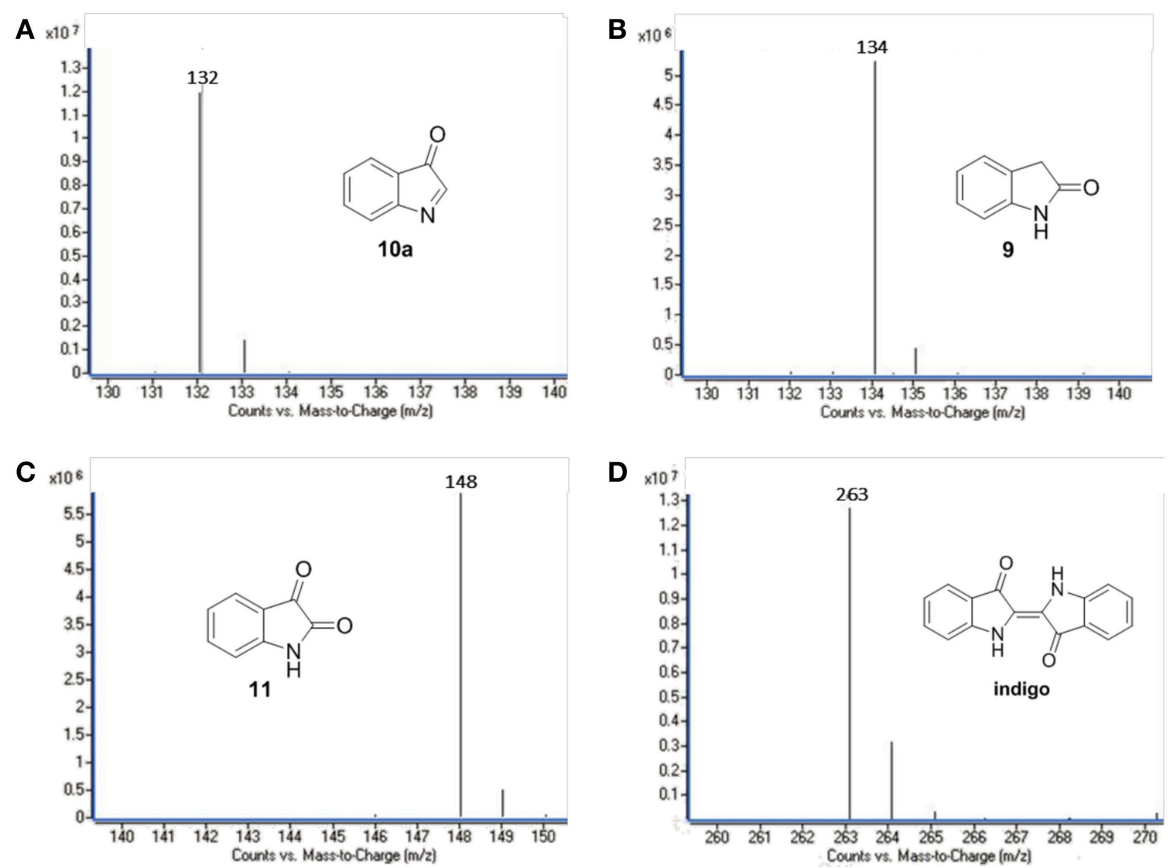

FIGURE 5 | LC-MS chromatograms of the major oxidation products: (A) 9, (B) 10a, (C) 11, and (D) indigo.

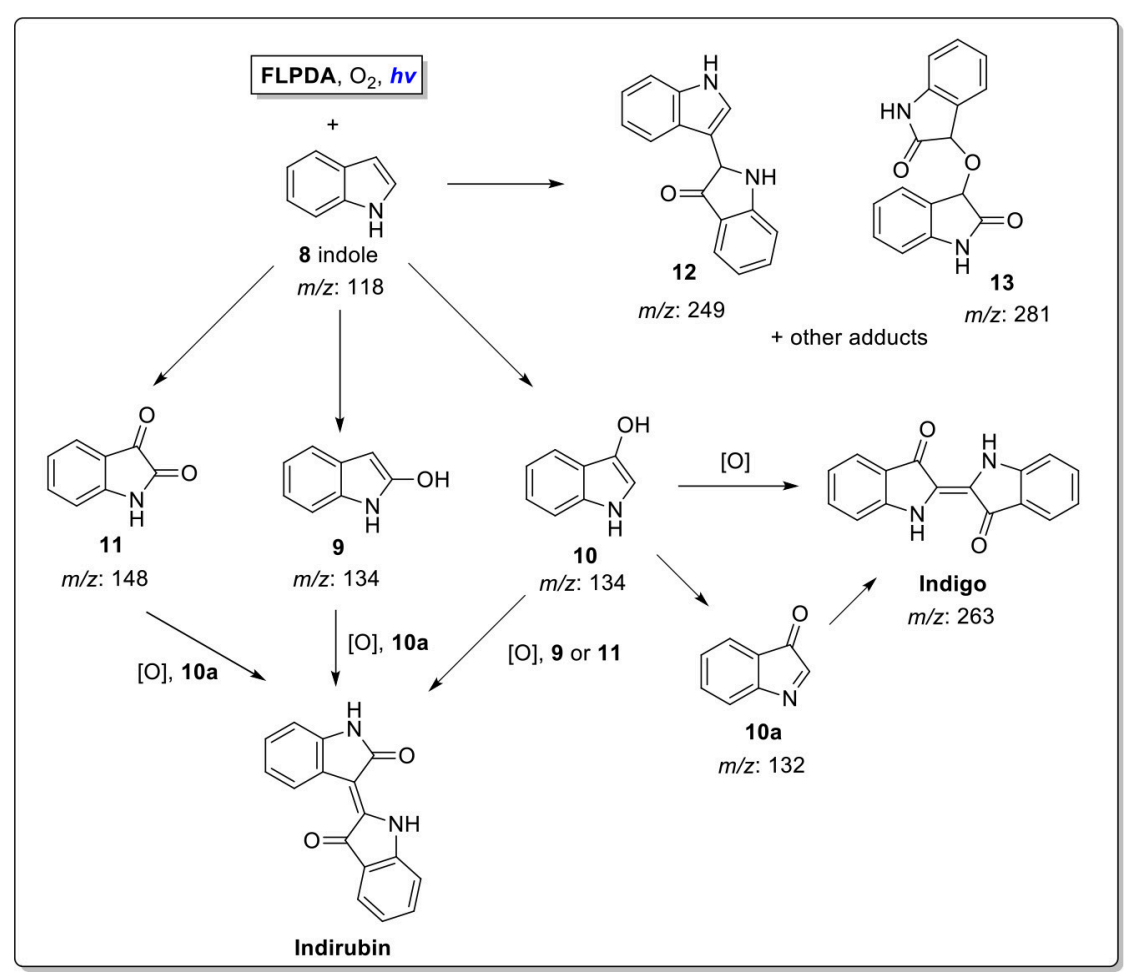

SCHEME 4 | Proposed reaction scheme for indole photooxidation in presence of enzyme mimicking FLPDA.

$0.5 \mathrm{~h}$. HPLC analysis indicated that there is a greater conversion of indole in presence of RF compared to FLPDA, and similar products although in different yields, were observed as shown in Figure 6 and Table 1. We next compared the yield of dyes after the reactions through the addition of 2 drops of $1 \mathrm{M} \mathrm{HCl}$ to each reaction mixture to initiate dimerization of hydroxylated 
TABLE 1 | Amounts and conversions of major compounds identified by HPLC after acidification of reaction mixture using commercial standards as a calibration reference.

\begin{tabular}{lccccc}
\hline Catalyst & $\begin{array}{c}\text { Indole } \\
(\boldsymbol{\mu} \mathbf{M})\end{array}$ & $\begin{array}{c}\text { Oxindole } \\
(\mathbf{9})(\boldsymbol{\mu} \mathbf{M})\end{array}$ & $\begin{array}{c}\text { Isatin (11) } \\
(\boldsymbol{\mu} \mathbf{M})\end{array}$ & $\begin{array}{c}\text { Indole } \\
\text { conversion }\end{array}$ & $\begin{array}{c}\text { Indigoid } \\
\text { yield* }^{*}\end{array}$ \\
\hline FLPDA & 213 & 22 & 60 & $79 \%$ & $5 \%$ \\
$(36 \mathrm{ug} / \mathrm{mL})$ & & 16 & 80 & $97 \%$ & $1 \%$ \\
$\mathrm{RF}(20 \mu \mathrm{M})$ & 24 & & & & \\
\hline
\end{tabular}

*([indigoid] $\times 2 /[$ consumed indole] $)(X u$ et al., 2012) with [indigoid] being determined by UV-Vis spectroscopy.

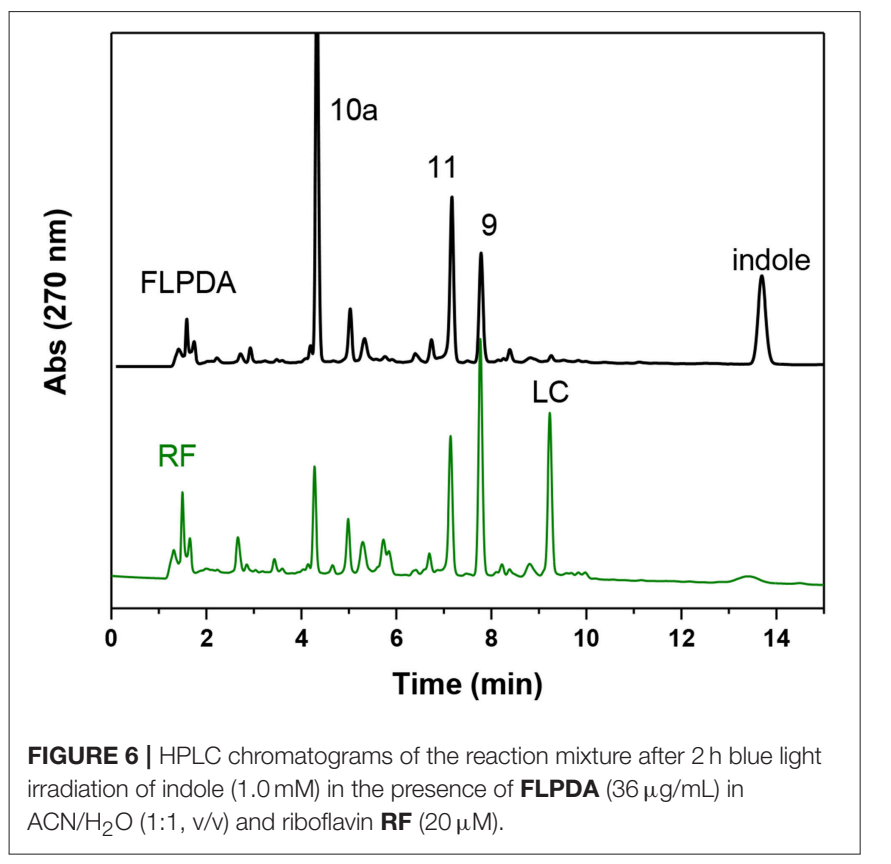

indole species to form the indigoid dyes. As shown in Figure 7B, there was more indirubin obtained from the reaction conducted in the presence of FLPDA than RF, which was expected as 2.5 times more precursor 10a can be detected in HPLC profile shown in Figure 6. Clearly, despite the decreased indole conversion, FLPDA appears to be more selective than its homogeneous counterpart toward dye conversion.

It is also worth noting that after the irradiation, RF could no longer be identified by TLC analysis within the reaction mixture and had degraded to lumichrome (LC), which was confirmed both by HPLC and LC-MS $(9.22 \mathrm{~min}, \mathrm{~m} / z$ : 243) (Figure 6). Although there was some photodecomposition observed in FLPDA, the concentration of lumichrome was five times lower compared to RF (based on HPLC integration), indicating that the hybrid catalyst offers more protection toward photodecomposition of active flavin centers, and mitigates the loss of catalysis observed in homogenous systems.

\section{Further Control Experiments and Possible Mechanism of Action}

As this is a novel hybrid system, we were also interested in unveiling the photocatalytic mechanism of FLPDA. To achieve this we employed a superoxide radical scavenger TEMPO and the singlet oxygen scavenger DABCO to quench these prominent reactive oxygen species (ROS) that may be liberated from reduced and/or photoexcited flavin species (Massey et al., 1969; Müller and Ahmad, 2011). As can be seen from the HPLC chromatograms of the reactions shown in Figure 8, the addition of these quenchers did not appear to inhibit the reaction completely. In fact, we observed that in the case of DABCO, the basic character of the species may have played a role in lowering the activity of FLPDA as flavins and PDA are less stable within a basic environment (Song et al., 1965; Yang et al., 2018). In terms of product selectivity, 10a was not detected most likely due to direct oxidization to isatin 11 in basic condition (Table 2). Based on these observations it could be assumed that singlet oxygen plays a minimal role in FLPDA activity as both compounds 9 and $\mathbf{1 1}$ are obtained in the presence of singlet oxygen quencher.

The addition to the superoxide scavenger, TEMPO had no deleterious effect on FLPDA activity either and in fact, it enhanced the production of $\mathbf{9}, \mathbf{1 0 a}$, and $\mathbf{1 1}$. In fact, TEMPO most probably acts as a redox mediator and co-catalyst in the reaction, as previously shown for the synthesis of isatin derivatives in the presence of hypervalent iodine (Sai Prathima et al., 2015). TEMPO's participation in the reactions was additionally proved by appearance of the by-product 2,2,6,6-tetramethylpiperidine (TMP) at a retention time of $2.49 \mathrm{~min}, \mathrm{~m} / z: 142$ (LC-MS analysis). It should be noted that pigment melanin, composed of PDA units, is capable of superoxide quenching (Tada et al., 2010), and it is safe to assume that any superoxide radical generated by flavin would be quickly quenched by PDA in its immediate proximity.

We further investigated the mechanism of FLPDA's photocatalytic activity by using a fluorescence-based assay to monitor the release of $\mathrm{H}_{2} \mathrm{O}_{2}$ liberated from the unstable $4 \mathrm{a}$ hydroperoxy-flavin species formed when reduced flavin moieties interact with oxygen (Usselman et al., 2014). We reasoned that the lower amount of $\mathrm{H}_{2} \mathrm{O}_{2}$ obtained in photo-reaction in presence of FLPDA compared to free flavin (riboflavin RF), would indicate potential stabilization of 4a-hydroperoxy-flavin species, and its interaction with indole (Scheme 5) instead of direct transformation into reactive oxygen species. To minimize the loss of photons due to the scattering effect of a colloidal heterogeneous catalyst, low concentration of FLPDA $(10 \mu \mathrm{g} / \mathrm{mL})$ was used, and the concentration of indole and effective concentration of free flavin were adjusted accordingly. The amount of $\mathrm{H}_{2} \mathrm{O}_{2}$ released after $1 \mathrm{~h}$ of irradiation was 3.62 $\pm 0.18 \mathrm{nmol}$ for FLPDA and $5.13 \pm 0.04 \mathrm{nmol}$ for RF (see Figure S4). The lower value obtained for FLPDA suggest that the stabilization of 4a-hydroperoxy flavin species in FLPDA may occur, although this hypothesis can only be fully confirmed after the completion of already initiated EPR study.

Based on current data, we propose the mechanism shown in Scheme 5, which includes the formation of the 4a-hydroperoxy species as a result of indole and/or PDA photoreduction, and subsequent interaction with oxygen. This species could be stabilized by $\mathrm{H}$-bonding with neighboring PDA moieties and be stable long enough to interact with the indole substrate. In addition, the appearance of compounds 12 and 13 indicates Type 1 photosensitization of indole through electron transfer to excited flavin moieties similar to that previously observed for riboflavin 

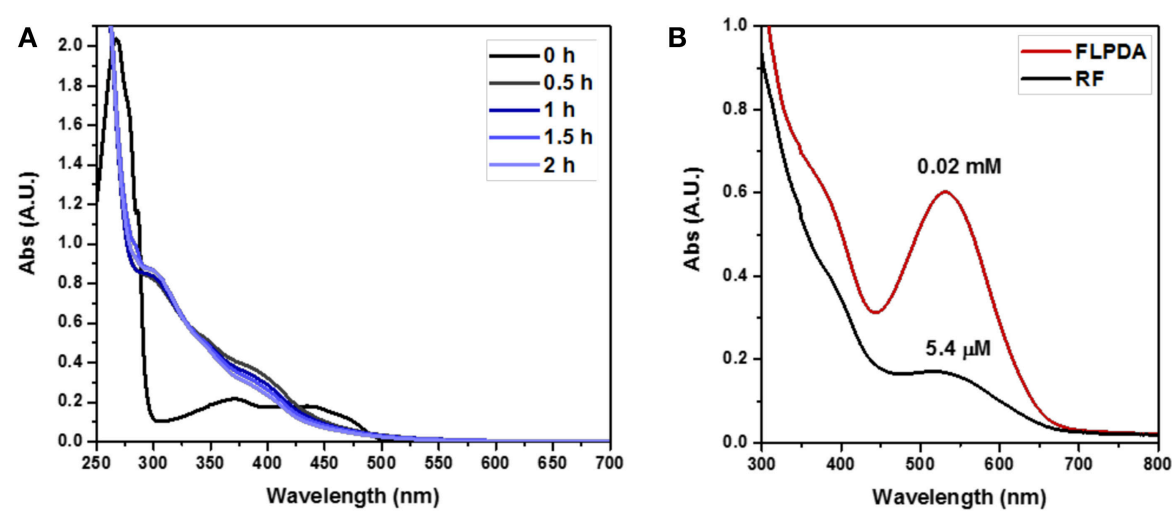

FIGURE 7 | (A) UV-Vis absorption spectra of the photooxidation of indole (1.0 mM) in the presence of $\mathbf{R F}(20 \mu \mathrm{M})$ in $\mathrm{O}_{2}$ saturated ACN/ $\mathrm{H}_{2} \mathrm{O}(1: 1$, v/v). (B) Plot comparing the reactions post acid workup ( $3 \times$ dilutions of reaction mixtures).

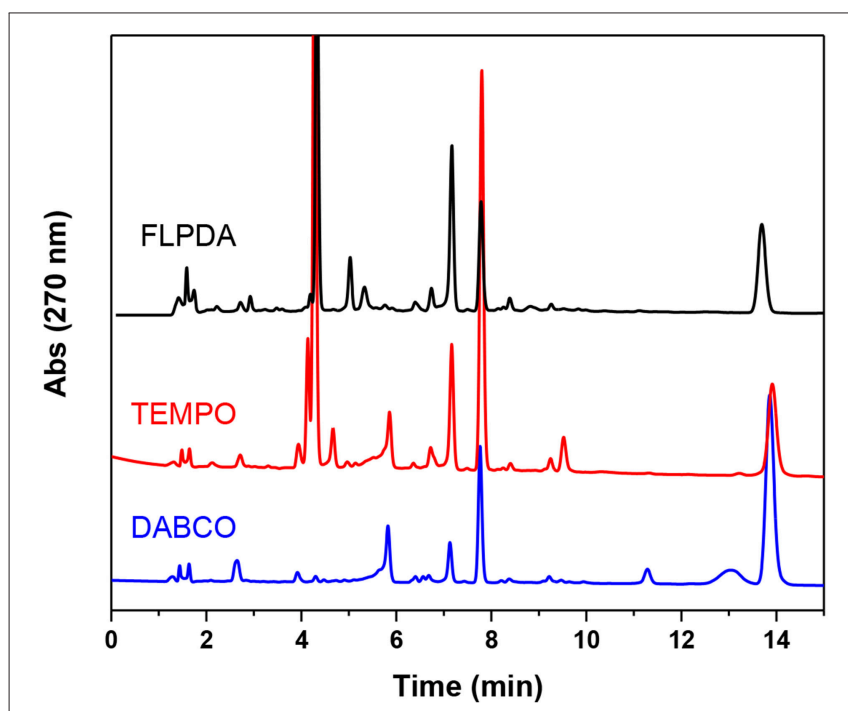

FIGURE 8 | HPLC chromatograms of control experiments in which FLPDA $(50 \mu \mathrm{g} / \mathrm{mL})$ and indole $(1.0 \mathrm{mM})$ were irradiated in presence of radical scavengers DABCO (1.0 mM) and TEMPO (1.0 mM).

TABLE 2 | Amounts and conversions of major compounds identified by HPLC after acidification of reaction mixture using commercial standards as a calibration reference.

\begin{tabular}{lcccc}
\hline Quencher & $\begin{array}{c}\text { Indole } \\
(\boldsymbol{\mu} \mathbf{M})\end{array}$ & $\begin{array}{c}\text { Oxindole } \\
(\mathbf{9}) \\
(\boldsymbol{\mu} \mathbf{M})\end{array}$ & $\begin{array}{c}\text { Isatin } \\
(\mathbf{1 1}) \\
(\boldsymbol{\mu} \mathbf{M})\end{array}$ & $\begin{array}{c}\text { Indole } \\
\text { conversion }\end{array}$ \\
\hline TEMPO & 177 & 278 & 121 & $82 \%$ \\
DABCO & 326 & 143 & 252 & $67 \%$ \\
\hline
\end{tabular}

and tryptophan (Silva et al., 2019). However, as stated above further studies using EPR spectroscopy are being undertaken to confirm our theory.

Although some "dark" reactions in the presence of flavin species have resulted in excellent yields of desired products (Arakawa et al., 2017; Chevalier et al., 2018), use of light to trigger the reaction cascade that leads to complex dye formation would have multiple advantages in an industrial setting, including temporal and spatial control, ultimately leading to the design of more efficient reactors.

\section{Recyclability}

Finally, we were interested to estimate the reusability of FLPDA in this light-driven reaction as this is a desirable property for scaling up and industrial applications enhancing the green potential of the system. Previous work on a heterogeneous flavin-based photocatalytic system using mesoporous silica to immobilize flavin moieties suffered from a severe loss of activity after the first reuse, and a complete inactivation upon second and third attempt (Špačková et al., 2017). For our nanoparticle-based system, the catalyst was easily removed from the reaction mixture via centrifugation and maintained activity for 4 cycles. As a proof of concept study, activity was monitored by irradiation of FLPDA particles $(50 \mu \mathrm{g} / \mathrm{ml})$ with indole $(1.0 \mathrm{mM})$ for $1.5 \mathrm{~h}$ and measuring the changes in absorption of the reaction mixture between 300 and $600 \mathrm{~nm}$ as shown in Figure 9A. The area within this region was integrated and used as a measure for oxidized indole species production. The first run showed a decrease in relative activity compared to the initial run only by a factor of 1.36 (Figure 9B) and the subsequent three runs stayed within a similar range before minimum activity, although not a complete loss, was observed by run 6.

The enhanced stability of our system could be explained by the electron transfer from PDA to flavin moieties upon irradiation as proposed in our mechanism (Scheme 5). It has already been shown that an addition of an electron donor, such as 2( $N$-morpholino)ethanesulfonic acid (MES) buffer, limits photoinduced decomposition reactions that curtail flavin activity upon irradiation (Alonso-De Castro et al., 2017). However, during the recycling steps, the number of retrieved particles decreased with each run. Loss of particles and the catalytic activity could point toward the photo-degradation of PDA moieties similar to what was previously observed in melanin samples (Ito et al., 2018). However, we did not notice any difference in the particle size and morphology after $2 \mathrm{~h}$ of irradiation (Figures 9C,D), which 

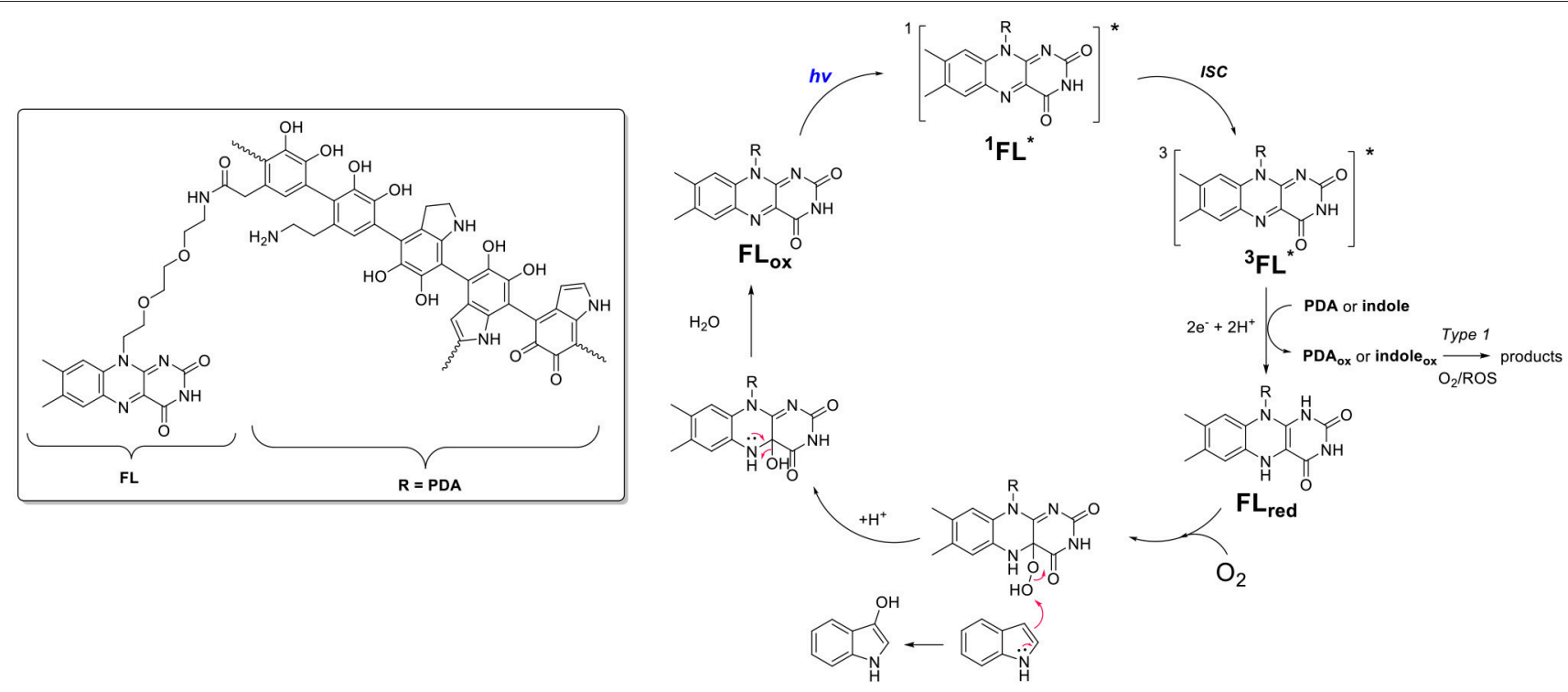

SCHEME 5 | Proposed mechanism of action involving electron transfer process between flavin (FL) and PDA moieties within FLPDA hybrid catalyst.

A

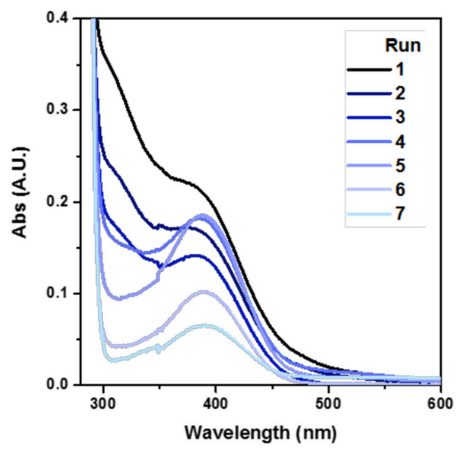

C

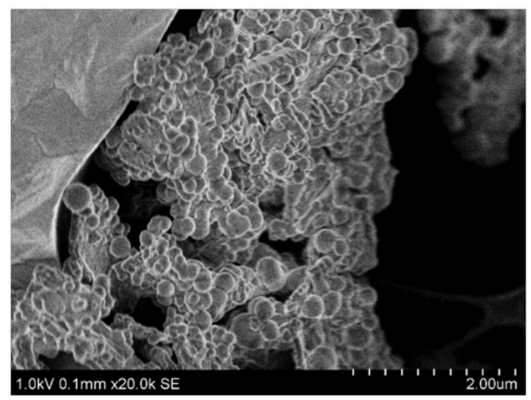

B

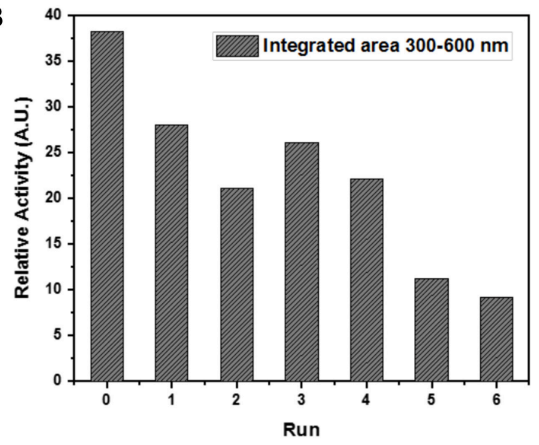

D

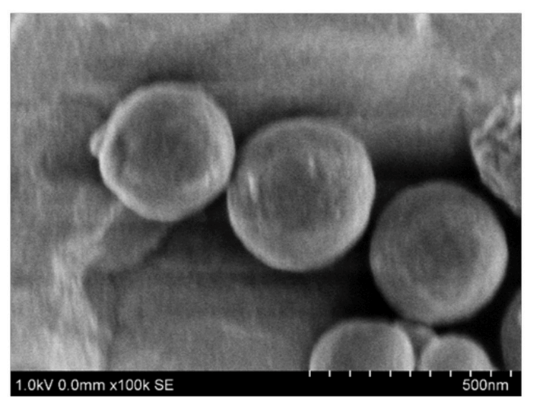

FIGURE 9 | Study of FLPDA catalyst recyclability. UV-Vis absorption spectra of different runs using a recycled catalyst (A) and the relative activity plot using the integrated area between 300 and $600 \mathrm{~nm}$ of each run (B). STEM image of FLPDA particles after $2 \mathrm{~h}$ irradiation shown at different scales (C) $\mathrm{scale}$ bar $=2.00 \mu \mathrm{m}$, and (D) scale bar $=500 \mathrm{~nm}$. Reaction conditions: indole $(1.0 \mathrm{mM})$, FLPDA $(50 \mu \mathrm{g} / \mathrm{mL})$ in $\mathrm{O}_{2}$ saturated $\mathrm{ACN} / \mathrm{H}_{2} \mathrm{O}(1: 1, \mathrm{v} / \mathrm{v})$ and irradiation for $1.5 \mathrm{~h}$.

disputes this argument, and indicates a mere physical loss of particles during recovery procedures.

Our ongoing work is focused on exploring the long-term stability and photo-degradation of FLPDA, as well as establishing a detailed mechanism using EPR studies. We believe this information will allow us to rationally design better catalytic systems with enantio-selective potential. We are also currently working on improving the reusability of FLPDA by addition of magnetic $\mathrm{Fe}_{3} \mathrm{O}_{4}$ nanoparticles during co-polymerization to enable magnetically aided retrieval, which has already proven effective in various application using PDA (Liu et al., 2013, 2017; Xie et al., 2014; Yu et al., 2016). 


\section{CONCLUSION}

We have developed a novel photocatalytic organic nanoparticle system made from flavin conjugated polydopamine. This was achieved through a convenient co-polymerization method involving dopamine and a flavin-dopamine analog, FLDA, to form FLPDA. The system effectively displays activity analogous to xenobiotic-degrading enzymes such as FMO, shown, using the oxidation reaction of indole, to form the indigo dye. In addition, it employs irradiation with visible light rather than an external cofactor for catalyst activation. The products observed in the reaction; indigo, indirubin, and related compounds, clearly indicated FMO-like activity of FLPDA. Additional ROS scavenging studies as well as the nature of some products, further confirmed that FLPDA displays mechanistic similarities to natural FMO, which is characterized by the formation of 4a-hydroperoxy flavin as a reactive intermediate. In contrast to our heterogeneous hybrid flavin, free flavin in a solution was characterized with higher photo-degradation and lower dye yields. In addition, FLPDA can easily be recovered from the reaction mixture and displays recyclable activity up to four cycles. We hope that this initial work sets the foundation to enable the design of more elaborate photocatalytic biopolymer hybrids comprising of flavin, PDA and additional functional moieties, to be applied in heterogeneous catalysis and artificial photosynthesis.

\section{REFERENCES}

Ai, K., Liu, Y., Ruan, C., Lu, L., and Lu, G. (2013). Sp2 C-dominant N-doped carbon sub-micrometer spheres with a tunable size: a versatile platform for highly efficient oxygen-reduction catalysts. Adv. Mater. 25, 998-1003. doi: 10.1002/adma.201203923

Alonso-De Castro, S., Ruggiero, E., Ruiz-De-Angulo, A., Rezabal, E., MarequeRivas, J. C., Lopez, X., et al. (2017). Riboflavin as a bioorthogonal photocatalyst for the activation of a PtIV prodrug. Chem. Sci. 8, 4619-4625. doi: $10.1039 / \mathrm{c} 7 \mathrm{sc} 01109 \mathrm{a}$

Arakawa, Y., Minagawa, K., and Imada, Y. (2018). Advanced flavin catalysts elaborated with polymers. Polym. J. 50, 941-949. doi: 10.1038/s41428-018-0089-8

Arakawa, Y., Yamanomoto, K., Kita, H., Minagawa, K., Tanaka, M., Haraguchi, N., et al. (2017). Design of peptide-containing: N 5-unmodified neutral flavins that catalyze aerobic oxygenations. Chem. Sci. 8, 5468-5475. doi: $10.1039 / \mathrm{c} 7 \mathrm{sc} 01933 \mathrm{e}$

Blackburn, R. S., Bechtold, T., and John, P. (2009). The development of indigo reduction methods and pre-reduced indigo products. Color. Technol. 125, 193-207. doi: 10.1111/j.1478-4408.2009.00197.x

Chevalier, Y., Lock Toy Ki, Y., le Nouen, D., Mahy, J. P., Goddard, J. P., and Avenier, F. (2018). Aerobic Baeyer-Villiger oxidation catalyzed by a flavincontaining enzyme mimic in water. Angew. Chem. Int. Ed. 57, 16412-16415. doi: $10.1002 /$ anie. 201810124

Cibulka, R. (2015). Artificial flavin systems for chemoselective and stereoselective oxidations. European J. Org. Chem. 2015, 915-932. doi: 10.1002/ejoc.201403275

de Gonzalo, G., and Fraaije, M. W. (2013). Recent developments in Flavin-based catalysis. Chem CatChem 5, 403-415. doi: 10.1002/cctc.201200466

Deng, L., Norberg, O., Uppalapati, S., Yan, M., and Ramström, O. (2011). Stereoselective synthesis of light-activatable perfluorophenylazide- conjugated carbohydrates for glycoarray fabrication and evaluation of structural effects on protein binding by SPR imaging. Org. Biomol. Chem. 9, 3188-3198. doi: $10.1039 / \mathrm{clob} 05040 \mathrm{k}$

\section{AUTHOR CONTRIBUTIONS}

LC carried out all the synthesis, characterization and analyses, and wrote the draft manuscript. LF was involved in the experimental planning and manuscript proofreading and corrections. LF was the academic lead of the project in charge of experimental planning and funding.

\section{FUNDING}

The project was funded by the Department of Chemical Engineering and Biotechnology Start-up grant awarded to LF. LC would like to acknowledge support for DTP-EPSRC doctoral programme (EP/N509620/1).

\section{ACKNOWLEDGMENTS}

We would like to thank Dijana Matak, as well as Rhian Preece, Nitin Rustogi, and Sabine Bahn for their help with LCMS analysis.

\section{SUPPLEMENTARY MATERIAL}

The Supplementary Material for this article can be found online at: https://www.frontiersin.org/articles/10.3389/fchem. 2019.00278/full\#supplementary-material

D’Ischia, M., Napolitano, A., Ball, V., Chen, C. T., and Buehler, M. J. (2014). Polydopamine and eumelanin: from structure-property relationships to a unified tailoring strategy. Acc. Chem. Res. 47, 3541-3550. doi: 10.1021/ar500273y

Du, Y., Yang, H. C., Xu, X. L., Wu, J., and Xu, Z. K. (2015). Polydopamine as a catalyst for thiol coupling. ChemCatChem 7, 3822-3825. doi: $10.1002 /$ cctc. 201500643

Erb, M., Veyrat, N., Robert, C. A. M., Xu, H., Frey, M., Ton, J., et al. (2015). Indole is an essential herbivore-induced volatile priming signal in maize. Nat. Commun. 6:6273. doi: $10.1038 /$ ncomms7273

Ganachaud, C., Garfagnoli, V., Tron, T., and Iacazio, G. (2008). Trimerisation of indole through laccase catalysis. Tetrahedron Lett. 49, 2476-2478. doi: 10.1016/j.tetlet.2008.02.021

Gehauf, B., and Goldenson, J. (1957). Detection and estimation of nerve gases by fluorescence reaction. Anal. Chem. 29, 276-278. doi: 10.1021/ac60122a029

Gillam, E. M. J., Notley, L. M., Cai, H., De Voss, J. J., and Guengerich, F. P. (2000). Oxidation of indole by cytochrome P450 enzymes. Biochemistry 39, 13817-13824. doi: 10.1021/bi001229u

Han, G. H., Gim, G. H., Kim, W., Seo, S., Il, and Kim, S. W. (2012). Enhanced indirubin production in recombinant Escherichia coli harboring a flavincontaining monooxygenase gene by cysteine supplementation. J. Biotechnol. 164, 179-187. doi: 10.1016/j.jbiotec.2012.08.015

Harayama, T., Tezuka, Y., Taga, T., and Yoneda, F. (1984). Hydrolysis products of flavins (isoalloxazines). Tetrahedron Lett. 25, 4015-4018. doi: 10.1016/0040-4039(84)80054-4

Heelis, P. F. (1982). The photophysical and photochemical properties of flavins (isoalloxazines). Chem. Soc. Rev. 11:15. doi: 10.1039/cs9821100015

Hodgson, E. (2010). Introduction to biotransformation (metabolism). Hayes Handb. Pestic. Toxicol. 2010, 865-875. doi: 10.1016/B978-0-12-374367-1.00036-7

Hong, S., Kim, K. Y., Wook, H. J., Park, S. Y., Lee, K. D., Lee, D. Y., et al. (2011). Attenuation of the in vivo toxicity of biomaterials by polydopamine surface modification. Nanomedicine 6, 793-801. doi: 10.2217/nnm.11.76 
Hsu, T. M., Welner, D. H., Russ, Z. N., Cervantes, B., Prathuri, R. L., Adams, P. D., et al. (2018). Employing a biochemical protecting group for a sustainable indigo dyeing strategy. Nat. Chem. Biol. 14, 256-261. doi: 10.1038/nchembio. 2552

Ito, S., Wakamatsu, K., and Sarna, T. (2018). Photodegradation of eumelanin and pheomelanin and its pathophysiological implications. Photochem. Photobiol. 94, 409-420. doi: 10.1111/php.12837

Jiang, X., Wang, Y., and Li, M. (2014). Selecting water-alcohol mixed solvent for synthesis of polydopamine nano-spheres using solubility parameter. Sci. Rep. 4:6070. doi: 10.1038/srep06070

Kim, J. H., Lee, M., and Park, C. B. (2014). Polydopamine as a biomimetic electron gate for artificial photosynthesis. Angew. Chem. Int. Ed. 53, 6364-6368. doi: 10.1002/anie.201402608

König, B., Kümmel, S., and Cibulka, R. (2013). Flavin photocatalysis. Chem. Photocatal. 3, 45-66. doi: 10.1515/9783110269246.45

Kotaki, A., Naoi, M., and Yagi, K. (1970). Effect of proton donors on the absorption spectrum of flavin compounds in apolar media. J. Biochem. 68, 287-292. doi: 10.1093/oxfordjournals.jbchem.a129358

Kotaki, A., and Yagi, K. (1970). Fluorescence properties of flavins in various solvents. J. Biochem. 68, 509-516. doi: 10.1093/oxfordjournals.jbchem.a129381

Kozik, A., Korytowski, W., Sarna, T., and Bloom, A. S. (1990). Interactions of flavins with melanin. Studies on equilibrium binding of riboflavin to DOPAmelanin and some spectroscopic characteristics of flavin-melanin complex. Biophys. Chem. 38, 39-48. doi: 10.1016/0301-4622(90)80038-9

Krueger, S. K., and Williams, D. E. (2005). Mammalian flavincontaining monooxygenases: structure/function, genetic polymorphisms and role in drug metabolism. Pharmacol. Ther. 106, 357-387. doi: 10.1016/j.pharmthera.2005.01.001

Kumar, A., and Kumar, S. (1998). Colloidal CdS-induced photocatalytic reaction of 2-methyl-indole-mechanistic analysis of oxidation of indoles. J. Phys. Org. Chem. 11, 277-282. doi: 10.1002/(SICI)1099-1395(199804)11:4<277::AID-POC3>3.0.CO;2-T

Kunfi, A., Szabó, V., Mastalir, Á., Bucsi, I., Mohai, M., Németh, P., et al. (2017). Palladium on polydopamine: its true potential in catalytic transfer hydrogenations and heck coupling reactions. ChemCatChem 9, 3236-3244. doi: $10.1002 /$ cctc. 201700609

Kuo, H. H., and Mauk, A. G. (2012). Indole peroxygenase activity of indoleamine 2,3-dioxygenase. Proc. Natl. Acad. Sci. U.S.A. 109, 13966-13971. doi: 10.1073/pnas.1207191109

Lee, H., Dellatore, S. M., Miller, W. M., and Messersmith, P. B. (2007). Musselinspired surface chemistry for multifunctional coatings. Science 318, 426-430. doi: 10.1126/science.1147241

Lee, J. H., Kim, Y. G., Baek, K. H., Cho, M. H., and Lee, J. (2015a). The multifaceted roles of the interspecies signalling molecule indole in Agrobacterium tumefaciens. Environ. Microbiol. 17, 1234-1244. doi: 10.1111/1462-2920.12560

Lee, J. H., and Lee, J. (2010). Indole as an intercellular signal in microbial communities. FEMS Microbiol. Rev. 34, 426-444. doi: 10.1111/j.1574-6976.2009.00204.x

Lee, J. H., Wood, T. K., and Lee, J. (2015b). Roles of indole as an interspecies and interkingdom signaling molecule. Trends Microbiol. 23, 707-718. doi: 10.1016/j.tim.2015.08.001

Li, S., Yang, X., Yang, S., Zhu, M., and Wang, X. (2012). Technology prospecting on enzymes: application, marketing and engineering. Comput. Struct. Biotechnol. J. 2:e201209017. doi: 10.5936/csbj.201209017

Lin, B., and Tao, Y. (2017). Whole-cell biocatalysts by design. Microb. Cell Fact. 16:106. doi: 10.1186/s12934-017-0724-7

Lin, C., Top, D., Manahan, C. C., Young, M. W., and Crane, B. R. (2018). Circadian clock activity of cryptochrome relies on tryptophan-mediated photoreduction. Proc. Natl. Acad. Sci. U.S.A. 115, 3822-3827. doi: 10.1073/pnas.1719376115

Lin, G. H., Chen, H. P., Huang, J. H., Liu, T. T., Lin, T. K., Wang, S. J., et al. (2012). Identification and characterization of an indigo-producing oxygenase involved in indole 3-acetic acid utilization by Acinetobacter baumannii. Antonie van Leeuwenhoek 101, 881-890. doi: 10.1007/s10482-012-9704-4

Linhares, M., Rebelo, S. L. H., Simões, M. M. Q., Silva, A. M. S., Neves, M. G. P. M. S., Cavaleiro, J. A. S., et al. (2014). Biomimetic oxidation of indole by $\mathrm{Mn}$ (III)porphyrins. Appl. Catal. A Gen. 470, 427-433. doi: 10.1016/j.apcata.2013.11.023

Liu, R., Guo, Y., Odusote, G., Qu, F., and Priestley, R. D. (2013). Core-shell $\mathrm{Fe} 3 \mathrm{O} 4$ polydopamine nanoparticles serve multipurpose as drug carrier, catalyst support and carbon adsorbent. ACS Appl. Mater. Interfaces 5, 9167-9171. doi: 10.1021/am402585y

Liu, S., Qileng, A., Huang, J., Gao, Q., and Liu, Y. (2017). Polydopamine as a bridge to decorate monodisperse gold nanoparticles on $\mathrm{Fe}_{3} \mathrm{O}_{4}$ nanoclusters for the catalytic reduction of 4-nitrophenol. RSC Adv. 7, 45545-45551. doi: $10.1039 / \mathrm{c} 7 \mathrm{ra09373j}$

Liu, Y., Ai, K., and Lu, L. (2014). Polydopamine and its derivative materials: synthesis and promising applications in energy, environmental, and biomedical fields. Chem. Rev. 114, 5057-5115. doi: 10.1021/cr400407a

Ma, A., Xie, Y., Xu, J., Zeng, H., and Xu, H. (2015). The significant impact of polydopamine on the catalytic performance of the carried Au nanoparticles. Chem. Commun. 51, 1469-1471. doi: 10.1039/C4CC08489F

Ma, Q., Zhang, X., and Qu, Y. (2018). Biodegradation and biotransformation of indole: advances and perspectives. Front. Microbiol. 9, 2625. doi: 10.3389/fmicb.2018.02625

Massey, V., Strickland, S., Mayhew, S. G., Howell, L. G., Engel, P. C., Matthews, R. G., et al. (1969). The production of superoxide anion radicals in the reaction of reduced flavins and flavoproteins with molecular oxygen. Biochem. Biophys. Res. Commun. 36, 891-897. doi: 10.1016/0006-291X(69)90287-3

Mataranga-Popa, L. N., Torje, I., Ghosh, T., Leitl, M. J., Späth, A., Novianti, M. L., et al. (2015). Synthesis and electronic properties of $\pi$-extended flavins. Org. Biomol. Chem. 13, 10198-10204. doi: 10.1039/c5ob01418b

Mathes, T., Van Stokkum, I. H. M., Stierl, M., and Kennis, J. T. M. (2012). Redox modulation of flavin and tyrosine determines photoinduced proton-coupled electron transfer and photoactivation of BLUF photoreceptors. J. Biol. Chem. 287, 31725-31738. doi: 10.1074/jbc.M112.391896

Mermod, N., Harayama, S., and Timmis, K. N. (1986). New route to bacterial production of indigo. Bio/Technology 4, 321-324. doi: 10.1038/nbt0486-321

Meyer, A., Würsten, M., Schmid, A., Kohler, HP, and Witholt, B. (2002). Hydroxylation of Indole by laboratory-evolved 2hydroxybiphenyl 3-monooxygenase. J. Biol. Chem. 277, 34161-34167. doi: 10.1074/jbc.m205621200

Mrõwczynski, R., Bunge, A., and Liebscher, J. (2014). Polydopamine-an organocatalyst rather than an innocent polymer. Chem. A Eur. J. 20, 8647-8653. doi: $10.1002 /$ chem. 201402532

Müller, P., and Ahmad, M. (2011). Light-activated cryptochrome reacts with molecular oxygen to form a flavin-superoxide radical pair consistent with magnetoreception. J. Biol. Chem. 286, 21033-21040. doi: 10.1074/jbc.M111.228940

Nagayama, H., Sugawara, T., Endo, R., Ono, A., Kato, H., Ohtsubo, Y., et al. (2015). Isolation of oxygenase genes for indigo-forming activity from an artificially polluted soil metagenome by functional screening using Pseudomonas putida strains as hosts. Appl. Microbiol. Biotechnol. 99, 4453-4470. doi: 10.1007/s00253-0146322-2

O'Connor, K. E., Dobson, A. D. W., and Hartmans, S. (1997). Indigo formation by microorganisms expressing styrene monooxygenase activity. Appl. Environ. Microbiol. 63, 4287-4291.

Rebelo, S. L. H., Linhares, M., Simões, M. M. Q., Silva, A. M. S., Neves, M. G. P. M. S., Cavaleiro, J. A. S., et al. (2014). Indigo dye production by enzymatic mimicking based on an iron(III)porphyrin. J. Catal. 315, 33-40. doi: $10.1016 /$ j.jcat.2014.04.012

Reetz, M. T. (2002). Directed evolution of selective enzymes and hybrid catalysts. Tetrahedron 58, 6595-6602. doi: 10.1016/S0040-4020(02)00668-3

Rieff, B., Bauer, S., Mathias, G., and Tavan, P. (2011). IR spectra of flavins in solution: DFT/MM description of redox effects. J. Phys. Chem. B 115, 2117-2123. doi: 10.1021/jp111334z

Sai Prathima, P., Bikshapathi, R., and Rao, V. J. (2015). Synthesis of isatin derivatives under metal free conditions using hypervalent iodine. Tetrahedron Lett. 56, 6385-6388. doi: 10.1016/j.tetlet.2015.09.124

Schmaderer, H., Hilgers, P., Lechner, R., and König, B. (2009). Photooxidation of benzyl alcohols with immobilized flavins. Adv. Synth. Catal. 351, 163-174. doi: 10.1002/adsc.200800576

Seixas De Melo, J., Moura, A. P., and Melo, M. J. (2004). Photophysical and spectroscopic studies of indigo derivatives in their keto and leuco forms. J. Phys. Chem. A 108, 6975-6981. doi: 10.1021/jp049076y

Silva, E., Barrias, P., Fuentes-Lemus, E., Tirapegui, C., Aspee, A., Carroll, L., et al. (2019). Riboflavin-induced Type 1 photo-oxidation of tryptophan using a high 
intensity $365 \mathrm{~nm}$ light emitting diode. Free Radic. Biol. Med. 131, 133-143. doi: 10.1016/J.FREERADBIOMED.2018.11.026

Singh, A., Singh Chauhan, N., Thulasiram, H. V., Taneja, V., and Sharma, R. (2010). Identification of two flavin monooxygenases from an effluent treatment plant sludge metagenomic library. Bioresour. Technol. 101, 8481-8484. doi: 10.1016/j.biortech.2010.06.025

Smith, S. B., and Bruice, T. C. (1975). Mechanisms of isoalloxazine (flavine) hydrolysis. J. Am. Chem. Soc. 97, 2875-2881. doi: 10.1021/ja00843a043

Song, P. S., Smith, E. C., and Metzler, D. E. (1965). Photochemical degradation of flavins. II. The mechanism of alkaline hydrolysis of 6,7dimethyl-9-formylmethylisoalloxazine1,2. J. Am. Chem. Soc. 87, 4181-4184. doi: 10.1021/ja01096a031

Špačková, J., Svobodová, E., Hartman, T., Stibor, I., Kopecká, J., Cibulková, J., et al. (2017). Visible light [2+2] photocycloaddition mediated by Flavin derivative immobilized on mesoporous silica. ChemCatChem 9, 1177-1181. doi: $10.1002 /$ cctc. 201601654

Sullivan, D. W., and Gad, S. E. (2014). "Indole," in Encyclopedia of Toxicology, 3rd edn, ed P. Wexler (Cambridge, MA: Acadmeic Press), 1030-1031. doi: 10.1016/B978-0-12-609386454-3.00860-5

Tada, M., Kohno, M., and Niwano, Y. (2010). Scavenging or quenching effect of melanin on superoxide anion and singlet oxygen. J. Clin. Biochem. Nutr. 46, 224-228. doi: 10.3164/jcbn.09-84

Tsoi, K. M., Dai, Q., Alman, B. A., and Chan, W. C. W. (2013). Are quantum dots toxic? Exploring the discrepancy between cell culture and animal studies. Acc. Chem. Res. 46, 662-671. doi: 10.1021/ar300040z

Usselman, R. J., Hill, I., Singel, D. J., and Martino, C. F. (2014). Spin biochemistry modulates reactive oxygen species (ROS) production by radio frequency magnetic fields. PLoS ONE 9:e93065. doi: 10.1371/journal.pone.0093065

Wang, L., Hu, Z.-Y., Yang, X.-Y., Zhang, B.-B., Geng, W., Van Tendeloo, G., et al. (2017). Polydopamine nanocoated whole-cell asymmetric biocatalysts. Chem. Commun. 53, 6617-6620. doi: 10.1039/C7CC01283G

Woo, H. J., Sanseverino, J., Cox, C. D., Robinson, K. G., and Sayler, G. S. (2000). The measurement of toluene dioxygenase activity in biofilm culture of Pseudomonas putida F1. J. Microbiol. Methods 40, 181-191. doi: 10.1016/S0167-7012(00)00123-8

Xie, Y., Yan, B., Xu, H., Chen, J., Liu, Q., Deng, Y., et al. (2014). Highly regenerable mussel-inspired $\mathrm{Fe}_{3} \mathrm{O}_{4} @$ polydopamine- $\mathrm{Ag}$ core-shell microspheres as catalyst and adsorbent for methylene blue removal. ACS Appl. Mater. Interfaces 6, 8845-8852. doi: 10.1021/am501632f
Xu, J., Shoji, O., Fujishiro, T., Ohki, T., Ueno, T., and Watanabe, Y. (2012). Construction of biocatalysts using the myoglobin scaffold for the synthesis of indigo from indole. Catal. Sci. Technol. 2, 739-744. doi: 10.1039/c2cy $00427 \mathrm{e}$

Yang, W., Liu, C., and Chen, Y. (2018). Stability of polydopamine coatings on gold substrates inspected by surface plasmon resonance imaging. Langmuir 34, 3565-3571. doi: 10.1021/acs.langmuir.7b03143

Yang, Z., Sun, J., Liu, X., Su, Q., Liu, Y., Li, Q., et al. (2014). Nano-sized polydopamine-based biomimetic catalyst for the efficient synthesis of cyclic carbonates. Tetrahedron Lett. 55, 3239-3243. doi: 10.1016/j.tetlet.2014.04.033

Yong, K. T., Law, W. C., Hu, R., Ye, L., Liu, L., Swihart, M. T., et al. (2013). Nanotoxicity assessment of quantum dots: from cellular to primate studies. Chem. Soc. Rev. 42, 1236-1250. doi: 10.1039/c2cs35392j

Yu, X., Cheng, G., and Zheng, S. Y. (2016). Synthesis of self-assembled multifunctional nanocomposite catalysts with highly stabilized reactivity and magnetic recyclability. Sci. Rep. 6:25459. doi: 10.1038/srep25459

Zelentskii, A. N., Fomin, G. V., Kutafina, N. V., and Berlin, A. A. (1970). The mechanism of oxidation of indoxyl and its analogs to indigo and indigoides. Bull. Acad. Sci. USSR Div. Chem. Sci. 19, 1105-1107. doi: 10.1007/BF01084331

Zhou, J., and Shephard, E. A. (2006). Mutation, polymorphism and perspectives for the future of human flavin-containing monooxygenase 3. Mutat. Res. Rev. Mutat. Res. 612, 165-171. doi: 10.1016/j.mrrev.2005. 09.001

Zhou, X., Jin, B., Luo, J., Gu, X., and Zhang, S. (2017). Photoreduction preparation of $\mathrm{Cu}_{2} \mathrm{O} @$ polydopamine nanospheres with enhanced photocatalytic activity under visible light irradiation. J. Solid State Chem. 254, 55-61. doi: 10.1016/j.jssc.2017. 07.007

Conflict of Interest Statement: The authors declare that the research was conducted in the absence of any commercial or financial relationships that could be construed as a potential conflict of interest.

Copyright (ㄷ) 2019 Crocker and Fruk. This is an open-access article distributed under the terms of the Creative Commons Attribution License (CC BY). The use, distribution or reproduction in other forums is permitted, provided the original author(s) and the copyright owner(s) are credited and that the original publication in this journal is cited, in accordance with accepted academic practice. No use, distribution or reproduction is permitted which does not comply with these terms. 